\title{
Edición en contextos de encierro: sentidos e interrogantes de publicar en la cárcel
}

\section{Publication in confined environments: meanings and questions about in-prison publishing}

\author{
DOI: https://doi.org/10.32870/dse.v0i23.760
}

\section{María José Rubín*}

\begin{abstract}
Resumen
La práctica editorial como trabajo de promoción de las voces de otros(as) adquiere un sentido particular en contextos de encierro, donde las y los sujetos son silenciados y dichos(as) por discursos ajenos, especialmente de la prensa y del propio sistema punitivo que los condena. En este contexto, proponer instancias de producción y publicación de un discurso propio permite abrir espacios de reflexión y acción en torno al posicionamiento enunciativo y subjetivo que disputan los sentidos impuestos desde el exterior. A partir de la experiencia desarrollada por el Taller Colectivo de Edición en penales federales de la Argentina desde hace más de diez años, proponemos algunos lineamientos que orientan nuestro trabajo como parte de un proyecto político-pedagógico y planteamos una serie de interrogantes en relación con aspectos de la práctica editorial intramuros.
\end{abstract}

Palabras clave: edición - cárceles - escritura - subjetivación - enunciación.

\begin{abstract}
Editorial practice as the work of promoting the voices of others acquires a particular meaning in confined environments, where people are silenced and narrated about through discourses from others, especially the press and the punitive system that condemns them. In this context, proposing instances of production and publication of the inmates' own discourse allows for spaces for reflection and action around the enunciating and subjective position disputed by the meanings imposed from the outside. Based on the experience developed by the Taller Colectivo de Edición (Collective Editing Workshop) in federal prisons in Argentina for over ten years, we propose some guidelines that guide our work as part of a political-pedagogical project as we raise a number of questions regarding aspects of the intramural publishing practice.
\end{abstract}

Keywords: editing - prisons - writing - subjectivation - enunciation.

* Licenciada en Crítica de Artes. Editora y doctorante en Letras, Facultad de Filosofía, Universidad Nacional de las Artes. Docente e investigadora en la Universidad Nacional de las Artes y Universidad de Buenos Aires. Integrante del Programa de Extensión en Cárceles. Coordinadora del Taller Colectivo de Edición. Miembro del comité organizador del Encuentro Nacional de Escritura en la Cárcel. Líneas de investigación: procesos editoriales en contextos de encierro y la constitución de colectivos editores en el marco de prácticas de extensión universitaria. Argentina. rubinmariajose@gmail.com 


\section{Presentación del proyecto}

Este trabajo forma parte de un proyecto de investigación que propone el estudio de publicaciones desarrolladas en contextos de encierro, en el marco de políticas y espacios de intervención universitaria en la cárcel. Su objetivo general es abordar materiales que aún no han sido documentados ni sistematizados desde una perspectiva editorial, es decir, atendiendo a los procesos de conceptualización y producción de objetos y relaciones culturales que constituyen la edición. De esta manera, se busca ejercer una labor crítica de recuperación de saberes que no solo refiera a los contextos de encierro, sino también a la potencia de la actividad de extensión como modo de intervención de la Universidad en la sociedad, que irradia hacia o se articula con otras instituciones y formas de organización.

Esta investigación tiene sus raíces en la práctica editorial desarrollada como parte del Programa de Extensión en Cárceles (PEC), dependiente de la Secretaría de Extensión Universitaria y Bienestar Estudiantil (SEUBE) de la Facultad de Filosofía y Letras (FFyL) de la Universidad de Buenos Aires (UBA). En concreto, se alimenta de las actividades llevadas a cabo en el marco del Taller Colectivo de Edición, un curso dictado en tres penales federales de la Argentina, que integra la programación extracurricular de la FFyL congregada en el PEC.

EI TCE funciona como un colectivo editor que publica tres revistas semestrales y como una propuesta pedagógica para personas privadas de su libertad, sin restricciones en cuanto a su trayectoria académica: cada cuatrimestre recibimos en las aulas estudiantes universitarios, a la par de estudiantes de escuela primaria y secundaria, así como personas no escolarizadas. Asimismo, el TCE también se constituye como un territorio de indagación teórica en el marco de proyectos de investigación UBACyT sobre escritura y contextos de encierro, radicados en el Instituto de Filología y Literatura Hispánica "Doctor A. Alonso", de la FFyL, UBA.

Este trabajo se inscribe como parte de los estudios del libro y la edición, un campo incipiente que congrega perspectivas disciplinares diversas, con foco en distintos aspectos de la práctica. Si bien la edición, entendida como industria cultural, es una perspectiva dominante, su abordaje en tanto práctica política contrahegemónica ha comenzado a alborear en el estudio de pequeños emprendimientos editoriales o de formas alternativas y contraculturales, con menor o nula incidencia de un horizonte de distribución comercial.

Es en este marco que proponemos considerar una práctica de creciente relevancia en los últimos 20 años. Durante este periodo, se ha observado un incremento en la edición de publicaciones en contextos de encierro -fundamentalmente, cárceles de adultos y adultas- en el territorio argentino, que se desarrollan como parte de propuestas pedagógicas o sociales, llevadas adelante por instituciones educativas y/u organizaciones civiles.

El ejercicio de la edición en instituciones penales, caracterizados como "el límite inferior del estado de derecho" (Parchuc, 2018: 68) por la sistemática vulneración de derechos que allí se observa, pone en evidencia su "carácter político" (Salgado, 2015: 5). En tanto práctica que 
legitima, visibiliza y así transforma el estatuto de los discursos a los que se aboca, es posible -y perentorio- orientarla en el sentido de una ampliación de derechos al poner sus operaciones al servicio de discursos y voces largamente silenciados y deslegitimados.

La edición en contextos de encierro resulta de interés para el campo de estudios de la edición, no solo por su importancia como actividad tendiente a la ampliación de derechos en espacios de gran vulneración, que permite redimensionar el rol de el/la editor, sino también porque la especificidad de este universo de prácticas editoriales y de los objetos culturales a los que dan origen, develan modos en que la edición produce sentido a ambos lados de la reja.

En particular, este trabajo se propone abordar los sentidos que construye la edición de publicaciones periódicas en contextos de encierro, atendiendo a las características de las publicaciones que produce y a la voz de las personas privadas de su libertad que conforman el colectivo editor. A partir de una propuesta que acerca la Universidad a través de distintas áreas, especialmente el equipo docente del TCE con apoyo de la Subsecretaría de Publicaciones de la Facultad, quienes asisten al taller aportan sus propios marcos de referencia, que dialogan y muchas veces confrontan los modos de trabajo y las concepciones de la labor editorial de las y los docentes y profesionales. Dar lugar y sostener este diálogo es lo propio de la actividad editorial en este contexto, entendida como una práctica político-pedagógica de promoción de las voces silenciadas por el encierro. Recuperar los sentidos puestos en juego como parte del trabajo de investigación, resulta clave para continuar retroalimentando la práctica y para contribuir a su conocimiento.

\section{Aspectos metodológicos}

En términos metodológicos, este trabajo abreva, por un lado, de la propia práctica editorial desarrollada como actividad a la vez pedagógica y comunicacional. En este sentido, se tomarán en cuenta los documentos producidos como parte de esta labor de formulación y realización de las publicaciones periódicas La Resistencia, en el Centro Universitario Devoto; Los Monstruos Tienen Miedo, en el Complejo Penitenciario Ezeiza I; y Desatadas, en el Complejo Penitenciario Ezeiza IV. En sentido estricto, estas revistas se producen en los centros universitarios de cada unidad, creados por convenio con la Universidad de Buenos Aires.

Estos documentos permitirán recuperar nociones, conceptos y sentidos puestos en juego durante la producción de las revistas, que refieren al imaginario que condiciona las decisiones tomadas colectivamente como parte de esta labor. En cada encuentro áulico, preguntarse y debatir en torno a las implicancias de estas decisiones para la construcción de la escena enunciativa en que se inscribirá la revista -en otras palabras, las consecuencias de lo decidido en el plano de la comunicación-, condensan las expectativas, las aspiraciones y los desafíos que la actividad editorial convoca en estos contextos (Gaudio, et al, 2013; Salgado, 2015). 
Como participante activa de esta labor, se hace también necesaria una mirada sobre cómo estas prácticas construyen "territorios pedagógicos" en contextos de encierro (Bustelo, 2017), una "forma de estar-en-la-educación" (Chauvin, 2016) que se contrapone a las estructuras y prácticas penitenciarias, pero también atenta contra "Ios supuestos, las concepciones acerca de los sujetos con los que trabajamos [...] que son los que orientan nuestras formas de proceder" (Petz, 2015: 3). Este aspecto resulta fundamental tanto en el momento de retornar al trabajo en el aula como para la propia investigación académica, ya que complejiza la observación y nos pone a resguardo de que nuestra perspectiva determine de antemano la lectura de los procesos a los que asistimos y que guiamos.

En tanto indagación de los materiales producidos, este trabajo requiere también de un marco teórico relacionado con la lectura como práctica anclada en objetos de la cultura. Se tomarán como referencia las investigaciones de Michel de Certeau (1980) y Roger Chartier (1993); y en el ámbito específico del contexto de encierro, trabajos que analizan los sentidos de la lectura y el acceso a los libros en prisión, su potencial para ampliar las posibilidades educativas y culturales, abrir recorridos menos "tutelados" y provocar encuentros entre los lectores (Frugoni, 2018: 116). Con el objetivo de abordar las formas en que la edición produce o trabaja con el sentido, se tomará en consideración la perspectiva de Hernán Vanoli, de la práctica editorial como "un tipo de activismo cultural" (2009: 162) y de proyectos que funcionan "como principios organizadores de comunidades de lectura" (2009: 173), en tanto permite atender a las maneras en que las decisiones editoriales piensan los horizontes de acceso y consumo de sus productos.

\section{La edición como práctica político-pedagógica y sus particularidades en contextos de encierro}

Qué es editar: marcas y operaciones de la transformación en el estatuto de lo escrito Existen numerosas formas de definir la actividad editorial: como industria cultural, parte del desarrollo productivo de un país o región; como emprendimiento singular, en tanto intervención en el campo de la cultura;' o como trabajo con la palabra ajena, con miras a su promoción y comunicación. En este trabajo interesa considerar esta última perspectiva, en tanto permite indagar en las prácticas realizadas como parte de propuestas pedagógicas que dialogan con, pero no integran de manera directa el circuito comercial que habitualmente se asocia a la pro-

1 "La actividad editorial es evocada con frecuencia o bien como una rama de las industrias culturales, dedicada a la industria del libro, donde prima su faceta comercial quedando la parte creativa o específicamente literaria en manos de los escritores, o bien en base a la caracterización de las actividades del editor, personaje mixto cuyos rasgos arquetípicos son entre otros, la potestad para intervenir los textos que se dedicará a publicar, su independencia con respecto de la puesta en circulación del producto en la librería, el control financiero de la publicación y, a veces, la iniciativa en la elaboración de proyectos de publicación, para lo cual puede convocar a diferentes autores" (Vanoli, 2009: 162). 
ducción de libros y revistas. En otras palabras, interesa indagar en los modos en que la edición opera con el sentido, al inscribir sus materiales en la esfera pública.

Al proyectar una publicación, la tarea editorial se constituye a partir de la pregunta por lectores ideales, por figuras autorales y por el tipo de diálogo -su tono, su registro- que se propone establecer entre ambos. El lugar de enunciación se constituye en una publicación a través de marcas presentes en los textos escritos, las ilustraciones y en la relación que establecen entre sí en la puesta en página, donde se jerarquizan los contenidos y se proponen recorridos de lectura.

Compartimos la perspectiva de Michel de Certeau, cuando refiere que leer...

... es peregrinar en un sistema impuesto (el del texto, análogo al orden construido de una ciudad o de un supermercado). [el lector] inventa en los textos algo distinto de lo que era su "intención". Los separa de su origen (perdido o accesorio). Combina sus fragmentos y crea algo que desconoce en el espacio que organiza su capacidad de permitir una pluralidad indefinida de significaciones (1980: 181-182).

Aún a sabiendas de que la lectura efectiva de sus productos es una práctica que queda fuera de su órbita, y que por lo tanto no puede predeterminar, la edición implica de todos modos un esfuerzo por establecer coordenadas de referencia en las que inscribir sus materiales. Antes de soltar amarras y dejar que la publicación vague sin rumbo definido, como "sistema de signos verbales o icónicos [...] que esperan sus sentidos del lector" (De Certeau, 1980: 181182), se esmera por entablar con él/ella no cualquier diálogo o relación, sino un debate en torno a ciertos temas, desde cierta perspectiva, proponiendo una enunciación experta o simétrica, distante o próxima.

La labor editorial comprende, entonces, la reflexión en torno a los aspectos, de muy diversa índole, que posicionan enunciativamente a una publicación. Desde la perspectiva de quienes ejercen ese acto enunciativo, este ejercicio remite también a su posicionamiento subjetivo: supone explorar posibilidades $y$, en el caso de sujetos cuya voz es a menudo silenciada o desautorizada, implica ampliar los horizontes de lo enunciable y de los lugares de enunciación que pueden construir mediante la escritura y la edición.

En este sentido, distintos tipos de productos editoriales vehiculizan escenas enunciativas diferentes: un fanzine, un libro cartonero, un libro de tapa blanda o tapa dura, una revista ilustrada con dibujos en blanco y negro o fotografía color; cada una es resultado de variables que enuncian de manera diversa y, por lo tanto, el posicionamiento en cada caso reviste sus propias particularidades.

Con esto en mente, resulta de interés atender algunos aspectos habituales de algunas publicaciones que se producen en contextos de encierro, en la medida en que estos objetos, se- 
gún sus características, proponen escenas de lectura y posicionan no solo sus contenidos sino, con ellos, a los colectivos o poblaciones que los produjeron.

\section{Publicaciones realizadas en contextos de encierro: rasgos comunes de un corpus heterogéneo}

Debido a la enorme diversidad de publicaciones que se producen intramuros, formular un corpus representativo constituye en sí mismo un desafío metodológico considerable. Un conjunto de objetos tal debería incluir desde una novela publicada por un sello editorial con presencia en librerías de todo el país, hasta un escrito de difícil clasificación, impreso en un solo pliego de hoja A4 y distribuido a cambio de una colaboración económica a voluntad. En el tránsito desde un extremo al otro del abanico, la práctica se aparta crecientemente de la lógica comercial, que sin embargo se hace presente en marcas que configuran el sentido de las publicaciones.

Consignar figuras autorales, establecer la forma del derecho de autor a la que se adscribe, indicar lugar y fecha de edición: estos elementos que protegen la potestad de los escritores a que se les reconozca la autoría de su obra y a percibir los dividendos correspondientes a su comercialización, suelen estar ausentes en publicaciones que se opongan a esta lógica de circulación, o cuando sus editores desconozcan o no encuentren necesidad de realizar trámites de catalogación y registro de los discursos que publican.

Estas marcas no funcionan exclusivamente como metadatos necesarios para la comercialización, sino que forman parte de un dispositivo de fuerte carga simbólica que inscribe sus textos en un diálogo con la cultura. Los ubica en un universo de géneros discursivos y de formatos editoriales que participan de una tradición, ya sea que la abracen o disputen sus sentidos, y los convierten muchas veces en obras - $y$ con ellos, a sus escritores en autores-. Al decir de Roger Chartier:

los puntos de referencia explícitos que designan y clasifican los textos crean, en relación a ellos, expectativas de lectura, anticipaciones de comprensión. Es lo que ocurre cuando se indica el género que relaciona el texto a leer con otros, ya leídos, y que señala al lector en qué pre-saber inscribirlo. Pero es lo que también ocurre con indicadores puramente formales o materiales: por ejemplo, el formato y la imagen. Del folio a los pequeños formatos existe una jerarquía que relaciona el formato del libro, el género del texto, el momento y el modo de lectura. También la imagen, en frontispicio o página de título, en el margen del texto o en su última página, clasifica el texto, sugiere una lectura, construye significación. Es protocolo de lectura, indicio identificador (Chartier, 1993: 50-51).

Estas marcas remiten a "operaciones" por las que una publicación llega a ser tal (Chartier, 1993: 29), por ellas sabemos que esos textos fueron seleccionados y tratados de tal modo que ya no pertenecen solamente a una esfera privada, en la que otros textos deban necesariamente 
reponerse para darle legibilidad. Lo publicado está concluido, se vale por sí mismo y ya no está restringido al diálogo o a las circunstancias en las que tuvo origen, sino que se inscribe en una discusión más amplia con la cultura.

Muchas de esas marcas se corresponden con un hacer editorial comercial y guardan las huellas de un proceso industrial: tanto por su materialidad, nacida de maquinarias de varios cuerpos sin rastros de la escritura manuscrita de su autor, como por códigos como el número de identificación estandarizado (ISBN), que dan por supuesta su distribución comercial. Esta evidencia estética de los modos industriales de producción de un libro y los signos relacionados con su inscripción en un mercado de bienes, tienen efectos de sentido también sobre el estatuto de lo enunciado a través de esas operaciones editoriales.

A medida que la comercialización como destino principal se ausenta de las prácticas editoriales que nos ocupan, los objetos que resultan de ellas tienden a distinguirse de las publicaciones estandarizadas del mercado. En consecuencia, su estatuto como publicaciones se ve afectado. Sus rasgos, tanto materiales (su tamaño, el grosor del papel, la factura de la cubierta) como metadiscursivos (los modos en los que remite a figuras autorales, a responsables editoriales, a su pertenencia a una colección, una serie, un género), enuncian de otra manera lo publicado en ellas.

Este tipo de operaciones también puede observarse en formatos editoriales de reconocida trayectoria, como los libros cartoneros y los fanzines. Tanto por el aspecto artesanal de su elaboración, que permite realizar el proceso de edición y fabricación íntegramente en espacios de taller, sin recurrir al circuito de producción industrial, y por los valores a los que se asocian estos formatos, muchas veces conforman el horizonte de las prácticas desarrolladas en contextos de encierro.

\section{Fanzines y libros cartoneros: formatos de referencia para la edición en contextos de encierro}

Con el objetivo de tomar distancia respecto de los modos de producción y enunciación editorial comerciales, proyectos como las editoriales cartoneras y numerosos movimientos contraculturales que apelaron al fanzine como herramienta de comunicación, trabajaron sobre la factura de sus publicaciones para diferenciarlas del formato de libro o revista propio de la industria editorial. Marcas de un trabajo artesanal, irreverencia a la normativa lingüística, reticencia a la identificación con géneros textuales y formatos editoriales reconocibles, estas estrategias son maneras de posicionarse contra la lógica comercial e industrial, pero también de visibilizar conflictos sociales -como las editoriales cartoneras surgidas en Argentina a partir de 2000-y de cuestionar los valores culturales instituidos -como los fanzines punk desde los años setenta.

El fanzine, en sus diversas formas, es un ejemplo paradigmático de publicación alternativa a la lógica de la industria cultural, entendida esta última como una actividad dedicada a 
la "producción de libros como usina de cultura" (Schmied, 2018: 9). El estatuto del fanzine se define por su ubicación en un borde respecto de la actividad editorial convencional. En tanto que vehículo tradicional para la difusión de la cultura escrita, el libro está destinado a perdurar, no solo como objeto sino principalmente como entidad que puede recuperarse mediante artefactos bibliográficos altamente estandarizados (ficha de catalogación, registro de propiedad intelectual, ISBN). Aún si el libro físico no pudiese hallarse, su memoria permanece disponible en bibliotecas, colecciones y registros estatales.

El fanzine, por el contrario, es efímero en los mismos términos en los que el libro es imperecedero: los modos de impresión y encuadernación utilizados en su factura le garantizan poca vida legible a los textos publicados, y las posibilidades de recuperar información sobre su existencia pasada se vuelven crecientemente remotas con el correr de poco tiempo. Lo que se publica en fanzines, entonces, no solo es imposible de comercializar por las vías previstas para el libro (no sería posible incluir un objeto tal en una cadena de distribución), sino que tampoco enuncia sus textos del mismo modo. Su circulación es menos independiente de autores y editores que la del libro, dotado de instrumentos que le otorgan autonomía para informar a cualquier lector cuál es su procedencia. El fanzine debe entregarse en mano, o tomarse de una mesa en un evento específico, para poder entender con la misma facilidad cuál es su origen y navegar por sus páginas, sin contratapas o índices que guíen el camino.

Durante los años posteriores a la crisis económica, social y política de 2001, en Argentina se desarrolló un fenómeno editorial que abrió nuevas posibilidades para la práctica editorial: las llamadas editoriales cartoneras. Eloísa Cartonera fue la primera experiencia conocida y la que marcó los estudios que proliferaron sobre este movimiento en los años que le siguieron. Sin embargo, el escenario de las editoriales cartoneras presenta una enorme diversidad de sentidos y modos de hacer, en parte debido a su veloz expansión a escala global.

[...] el concepto "editorial cartonera" [...] ha sido apropiado de manera distinta en cada lugar, en consonancia con el enfoque que explica que los procesos de globalización no necesariamente implican homogeneización. Al menos el caso de las editoriales cartoneras muestra una adopción de prácticas iguales o similares con variación de sus significados o, directamente, de prácticas diferentes (Kunin, 2013: 13).

Estos proyectos tienden a compartir, pese a su gran diversidad, la herencia del lema "hágalo usted mismo" (retomado de las vanguardias artísticas) que también identificó a los movimientos de fanzines punk de la década de 1970 (Canosa, 2017: 3), así como “Un discurso a favor de la descentralización de la literatura" (Kunin, 2013: 13).

Matapalo, Cartonerita Solar, Canita, Yerba Mala, La Cartonera y Sarita han expresado una intención ya sea de llevar o de producir literatura fuera o lejos de los lugares por donde generalmente circula (y así 
se localizan en centros de detención, bares, mercados, puertos o a ciudades que no son los centros culturales urbanos o las capitales de sus determinados países) (Kunin, 2013: 13-14).

Santiago Venturini considera que las editoriales cartoneras funcionan como precursoras de otro tipo de proyectos, como la Colección Chapita, que "produce libros en los márgenes de la industria y el mercado editoriales" (Venturini, 2015: 2), principalmente traducciones que hacen uso del argot rioplatense (presente en el doble sentido de la palabra "chapita"), identificables porque "cada tapa realizada en forma artesanal lleva una chapita incrustada" (Canosa, 2017: 4). Venturini señala que...

... luego de la consolidación de formaciones que pueden considerarse relevantes para su surgimiento -como el de las editoriales cartoneras- aparece en 2009 Colección Chapita [...] Esos libros, producto de un trabajo manual, exponen la manufactura y hacen de ella un valor, al igual que la artesanía. Por eso mismo escapan a lo institucionalizado, escapan al control editorial y la descripción bibliográfica: no cuentan con una página de legales, no consignan datos editoriales, no tienen ISBN (Venturini, 2015: 1-3).

Estos modos de hacer editorial, que circulan y se recrean en distintas experiencias a lo largo de los años, se ubican activamente en el margen, no como posición relegada sino como opción ética y estética. Así, funcionan en muchos casos como referentes de prácticas que habitan los márgenes de otra manera, como imposición y no como elección. La particularidad del contexto de encierro requiere prestar especial atención a esta compleja relación entre proyectos o perspectivas que comparten una voluntad de ensanchar las posibilidades de la práctica editorial, pero en circunstancias diversas.

\section{Observaciones en torno a la enunciación del Taller Colectivo de Edición en cárceles}

El Taller Colectivo de Edición debe su nombre al carácter horizontal y compartido de la actividad que propone en el marco de una práctica político-pedagógica:

De esta manera, las clases en principio expositivas pasaron a ser mayormente prácticas; los saberes de los participantes, muchos de los cuales tenían experiencias editoriales previas, asistían a otros cursos extracurriculares en el CUD, o cursaban otras carreras, fueron incorporados a la discusión al mismo nivel que los saberes de los coordinadores para construir conocimientos de manera colectiva y así materializarlos en la producción de la revista (Gaudio, et al., 2013).

Tal y como relatan en la cita anterior las y los coordinadores que dieron origen a esta modalidad del taller, este modo de trabajo se opone a una forma de organizar la labor que delegue a 
una figura docente la responsabilidad de tomar decisiones y dirimir sentidos durante el tiempo en el aula destinado a la edición de la revista. Asimismo, busca responder y constituirse en alternativa "a los procesos de infantilización, la 'pedagogía de la irresponsabilidad' (Segato, 2003) y la verticalidad del ámbito penitenciario" proponiendo, en contraste, "un funcionamiento que no jerarquice ni cristalice los roles requeridos por la tarea editorial" (Rubín, 2020: 117). En este posicionamiento respecto de las prácticas hegemónicas que funcionan como su referencia -la educación tradicional y el tratamiento penitenciario-, el taller encuentra a la vez su límite y su potencia.

Editar una publicación que se constituya en vehículo de la enunciación del colectivo supone mantener abierto el diálogo de manera permanente en torno a las percepciones, opiniones, deseos y pareceres de las personas que lo integran. Durante los incesantes intercambios que se entablan en el aula como parte de la práctica editorial del taller, se oponen perspectivas y se construyen concesos temporales, con miras a la toma de decisiones que corresponden al número de la revista en curso, a sabiendas de que las discusiones se reabrirán luego como parte de una nueva constitución del colectivo en torno al siguiente número de la publicación.

En este apartado, interesa recuperar escenas y discusiones que permitan poner de relieve los argumentos del colectivo editor en sus diversas configuraciones, en torno a los aspectos enunciativos de las publicaciones en las que trabaja. Son estas voces las que guían las prácticas editoriales desarrolladas por el TCE y las que sus revistas buscan promover.

\section{Críticas y reformulaciones a números previos: argumentos y decisiones del colectivo} Como parte de la actividad desarrollada en el Taller Colectivo de Edición, cada semestre retomamos la práctica en el aula leyendo y evaluando la edición anterior. Esto nos permite establecer un punto de partida para la nueva edición y entablar un diálogo con la historia del taller y su producción. De esta manera, la revista funciona como "soporte de una memoria del colectivo" (Rubín, 2019): es portadora de una identidad que se mantiene más allá de quiénes asisten al taller en un semestre determinado. A través de su historia, el colectivo se reconfigura y a la vez permanece repensándose sin desconocer su pasado, sino más bien nutriéndose de este.

Es en este primer trabajo semestral con las revistas que suelen surgir debates particularmente centrados en la escena enunciativa en la que el colectivo desea inscribir la nueva edición.

En 2014, el taller desarrollado en el Centro Universitario Devoto, donde editamos La Resistencia, comenzó con la observación, por parte de integrantes del colectivo, de la ilustración a doble página publicada en el número 9 de la revista, editado durante el semestre anterior. La ilustración mostraba un guerrero de ojos enrojecidos, dibujado en lápiz, que sostenía en su mano una espada. De esta se veían, en verdad, solo la empuñadura y parte de la hoja, debido a su disposición en la página. La mano del guerrero mostraba además un anillo que se asemejaba al dibujo de cinco puntos, típicamente carcelario, muchas veces tatuado o pintado en muros. 


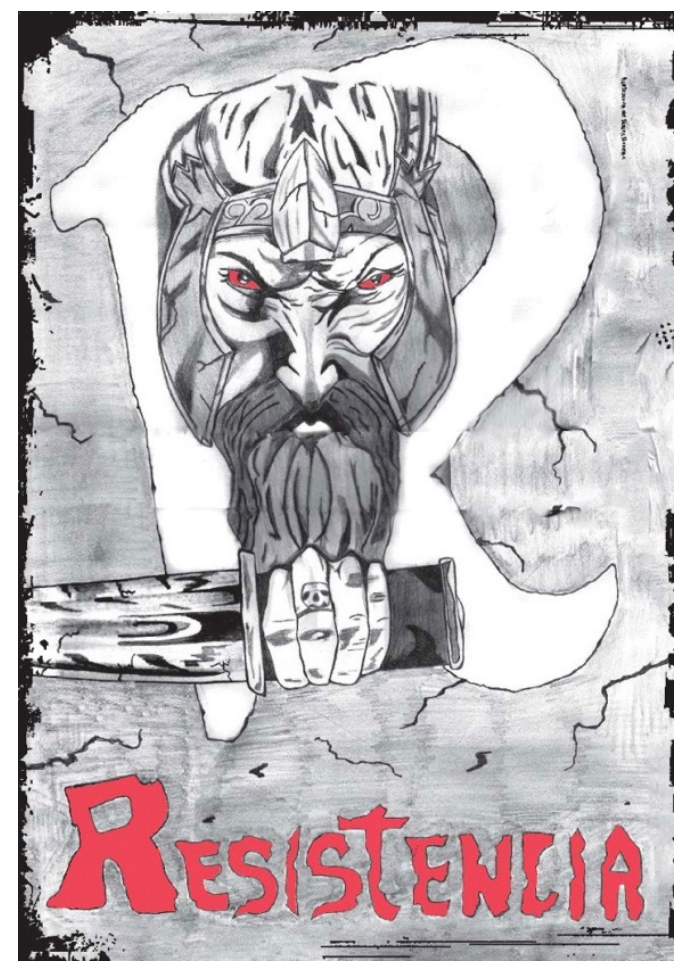

La Resistencia 9, diciembre de 2013. Ilustración de Maury Moreno, doble página central.

La ilustración despertó la preocupación de una parte del colectivo editor, que la consideraba violenta y estrechamente vinculada con un imaginario de la cárcel que no les interesaba promover. Otros, en cambio, que habían participado de la decisión de incluir esta imagen en el número anterior, consideraban que había sido suficientemente estilizada y que la figura del guerrero remitía a una lucha enaltecida, entre otros rasgos, señalada por la espada que blandía. En respuesta, los detractores de esta ilustración afirmaron que, por la puesta en página, que no permitía ver la espada en toda su longitud, parecía más bien que el guerrero portaba una "faca" o un "filo", es decir, un arma blanca fabricada de forma casera para defenderse en posibles riñas del pabellón. En particular, algunos esgrimieron que la procedencia de la revista, realizada en la cárcel, inclinaría la lectura en ese sentido, explicitando un límite necesario para la construcción de la escena enunciativa.

En el marco de estas discusiones surgió una dicotomía que se reactualizaría a lo largo de los años, aunque con diferentes matices, durante las discusiones en torno a la enunciación de las revistas: el par "más tumbero/menos tumbero" -es decir, más o menos identificable con la estética carcelaria- que desde entonces forma parte de los debates de cada semestre, no solo para quienes editan La Resistencia, sino también las otras revistas que produce el TCE. 
Como respuesta a aquel número de la revista, que portaba otros elementos cuestionados por los nuevos participantes del colectivo, se publicó un número 10 de La Resistencia, ilustrado casi enteramente por versiones de famosas obras de arte. Estas producciones habían sido recientemente pintadas en diversos espacios del centro universitario por Waikiki (Gastón Brossio), estudiante de Letras e integrante, con otros compañeros del centro universitario, del colectivo Pensadores Villeros Contemporáneos (PVC).

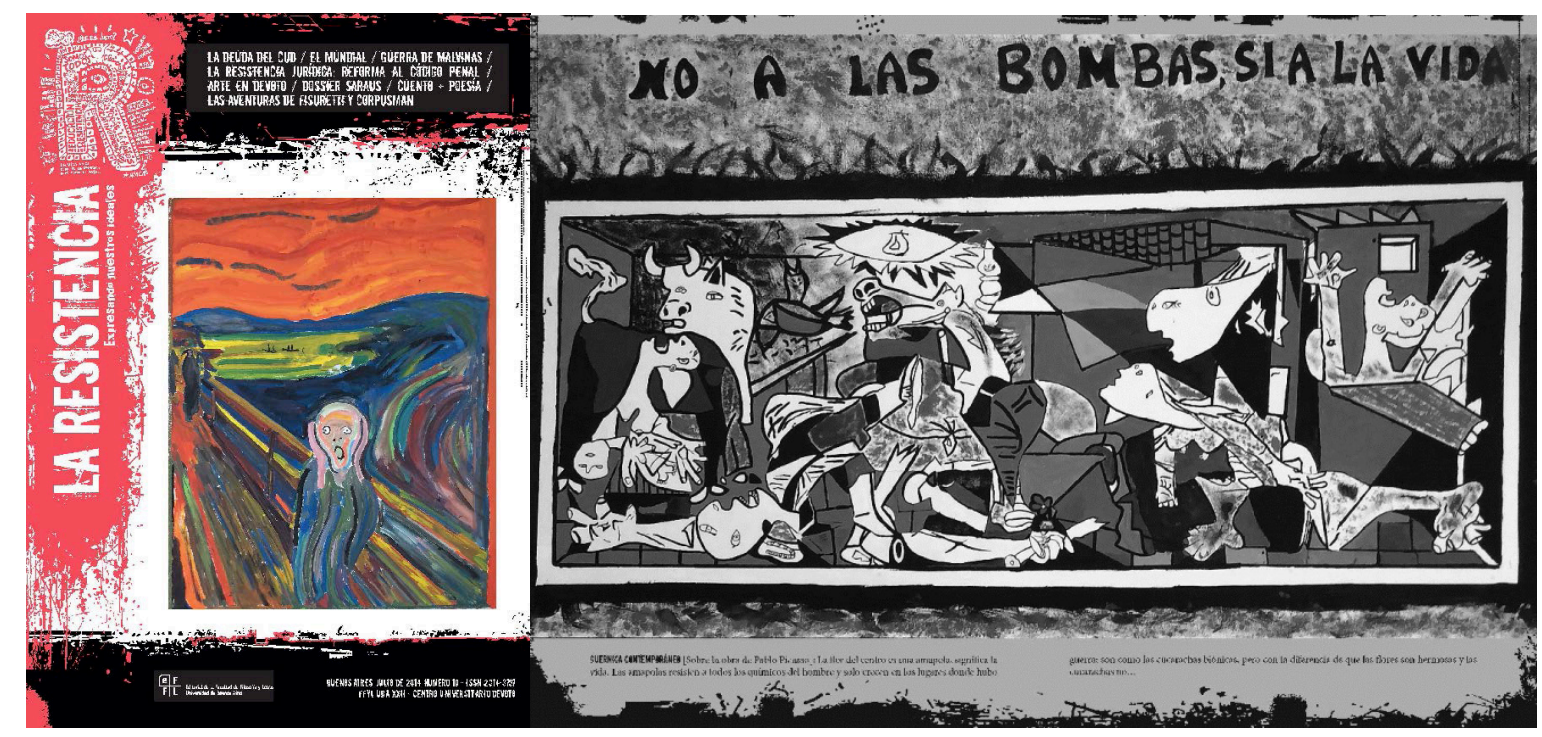

La Resistencia 10, julio de 2014. Tapa y doble página central.

Desde sus inicios en 2013, Los Monstruos Tienen Miedo incluye entre sus páginas ilustraciones realizadas por niños y niñas, en su mayoría hijos(as), sobrinos(as) o nietos(as) de los integrantes del colectivo editor, que les regalan dibujos como parte de intercambios epistolares o durante las visitas familiares. A partir del segundo número, publicado en 2014, estas producciones se sistematizaron en la sección "Los monstruitos de la revista". Durante varios años se publicaron en las retiraciones de contratapa de la publicación, impresas en cuatricromía, por lo que los dibujos podían lucirse en color. Desde mediados de 2018, sin embargo, por razones presupuestarias las retiraciones de tapa y contratapa comenzaron a imprimirse solo en tinta negra.

Ante esta nueva situación, el colectivo sostuvo durante el segundo semestre de ese año la pregunta por cómo proceder. Surgieron dos escenarios posibles. Por un lado, Los Monstruitos podían mantener su lugar en la revista, en cuyo caso los dibujos perderían el color, y los familiares, especialmente las y los más pequeños, recibirían una revista en la que sus aportes se verían sensiblemente deslucidos y relegados; por otro, podíamos reubicar la sección en el único lugar de la revista que aún conservaba el color: la contratapa, lo cual implicaba ceder un espacio clave de la publicación, superado en jerarquía solo por la tapa. En ese espacio habíamos 
publicado hasta la fecha textos e historietas con mensajes de vida, retratos de figuras que representaban las convicciones políticas del colectivo, y piezas estimadas en el taller por su valor artístico.

La pregunta era, finalmente, a quién privilegiábamos como interlocutor de la revista: a las familias o a una audiencia más amplia, y qué le estaríamos diciendo a esa audiencia en el caso de que nuestra decisión no la priorizara. Un debate semejante había surgido meses atrás, durante la edición del número 10 de Los Monstruos..., cuando nos preguntamos por las recetas que publicaríamos: ¿algo que se pueda preparar en el pabellón? ¿Algo para que preparen las familias? ¿Algo que resulte apetitoso a un lector con más recursos, pero que ni en el pabellón ni en las casas de los familiares se pudiese preparar? Teníamos el antecedente de haber optado por recetas posibles para las familias, pero en esta nueva discusión sobre Los Monstruitos se ponía en juego de forma aún más significativa el horizonte enunciativo de la revista: corríamos el riesgo de convertirnos en una publicación interna, señalaron algunos compañeros, solo destinada a circular en la cárcel y para la cárcel, para sus habitantes y sus allegados. Nos arriesgábamos a volvernos una publicación endémica.

Otros, por el contrario, consideraron que Los Monstruitos mostraba un lado de la cárcel que merecía ser visibilizado: que las voces de los niños y las niñas que debían ingresar al complejo penitenciario para poder compartir un momento con sus padres también eran silenciadas, como las suyas propias, y que incluso sería bueno que la audiencia más amplia encontrase que no solo se le habla a ella. Como resultado de este debate, desde el número 12 de la revista, Los Monstruitos lucen sus colores en las contratapas.

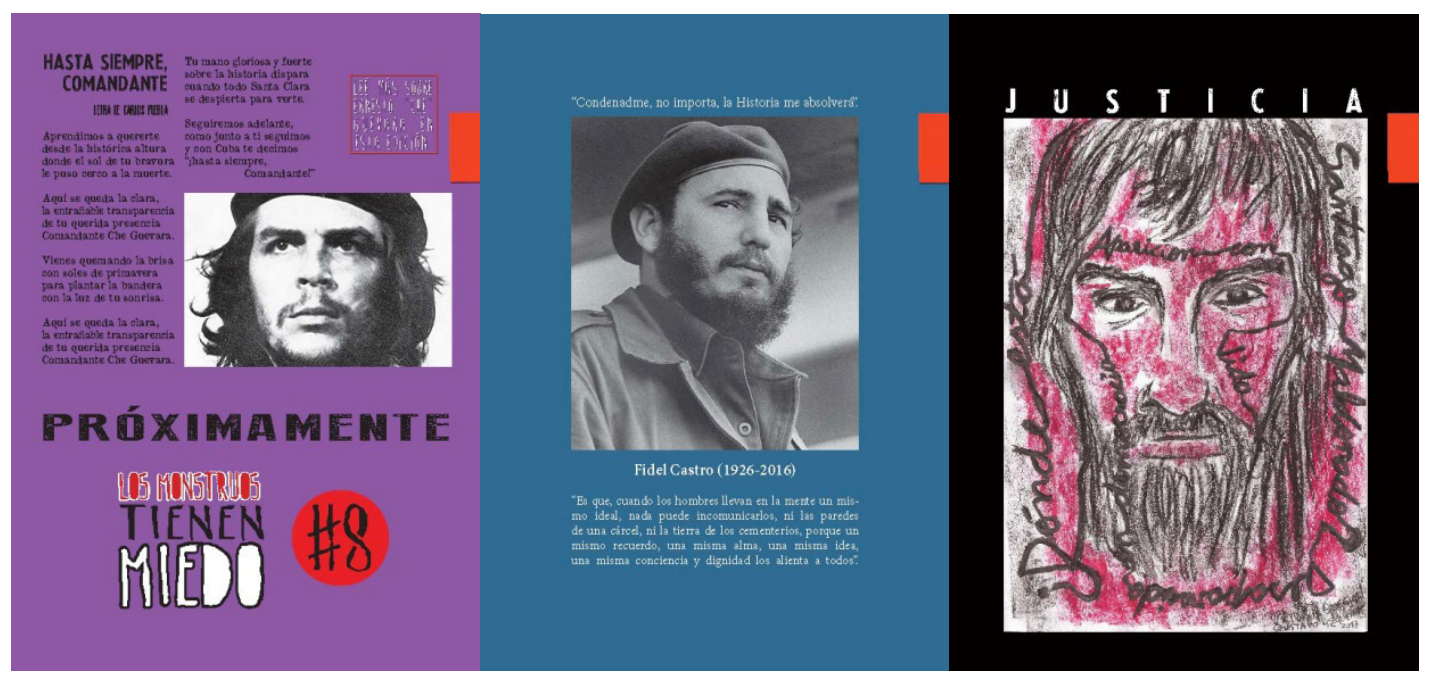

Los Monstruos Tienen Miedo 7, 8 y 10. Contratapas. 


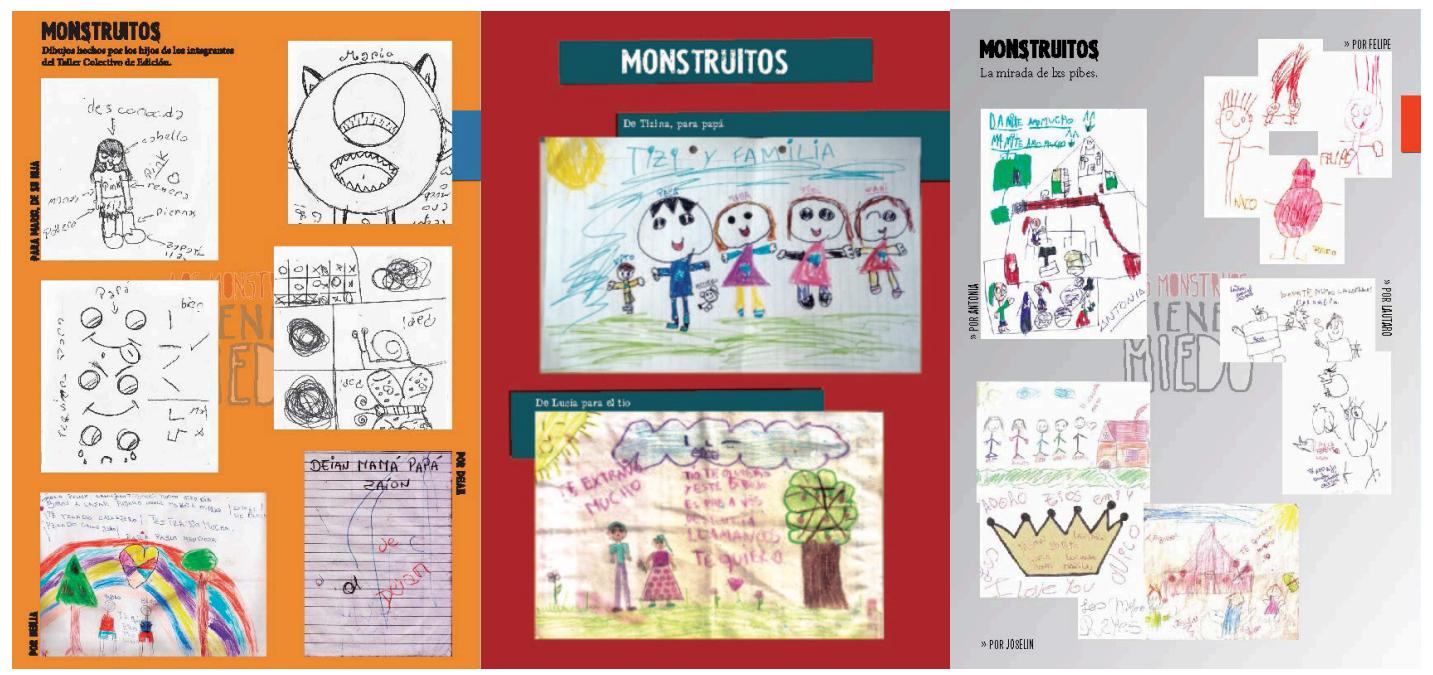

Los Monstruos Tienen Miedo 12, 13 y 14. Contratapas.

Durante el año 2019, el TCE inauguró una nueva instancia del taller y, con ella, una nueva revista: Desatadas, en el centro universitario del complejo federal de Ezeiza de mujeres. Como parte del trabajo para la nueva publicación, tuvimos la oportunidad de contar con la colaboración de un diseñador gráfico profesional que, de manera externa, propuso una plantilla de base a partir de la cual diagramamos la primera revista. El tamaño de las páginas, cercanas al estándar A4 (21cm. de ancho y $29.7 \mathrm{~cm}$. de alto) y la limitación de imprimir con una sola tinta (negra), normalmente hace que busquemos maneras de contrarrestar los grandes espacios blancos de la hoja. Las compañeras del taller, sin embargo, ante la primera revista impresa tuvieron otra percepción: el papel parecía manchado, las ilustraciones de fondo ensuciaban más que acompañaban el texto. La crítica más extendida fue a esta decisión, por lo que la segunda edición contó con páginas mucho más blancas, que tuvieron una mejor aceptación.

Tiempo más tarde, durante un evento en el que entregamos diplomas por la participación en el taller, una de las compañeras nos obsequió canastas elaboradas con papel. Algunas de ellas, plateadas y brillantes, llamaron nuestra atención especialmente, pero otra compañera hizo oír su crítica: eran "tumberas", estaban elaboradas con papel recuperado de los paquetes de cigarrillos, hacían uso de elementos que de otro modo se descartarían. Resultó notable que esas canastas, que por el trabajo manual y de reciclaje que implicaban nos habían resultado valiosas, en el contexto del penal se ubicaran demasiado cerca del polo "más tumbero" en el eje que ya hemos enunciado.

Resulta significativo en este marco poner en relación ambas críticas, ya que permiten entender a qué referencias se contraponen las páginas blancas que las integrantes del taller en 2019 desearon para su revista. El papel, como un recurso escaso en la cárcel, Ileva habitualmente a la reutilización de materiales que conservan las marcas de su uso original, como packging de 
productos consumibles, por ejemplo. La escritura en estos soportes, no elegidos sino impuestos por el contexto, se opone a la impresión de una revista para la que resulta posible decidir, en cambio, si la hoja será blanca o gris. La hoja blanca impresa se contrapone también al papel reutilizado, viejo, percudido, imperfecto, y su factura industrial enuncia la revista de un modo diferente a los procesos manuales, artesanales, que son los únicos disponibles en el encierro.

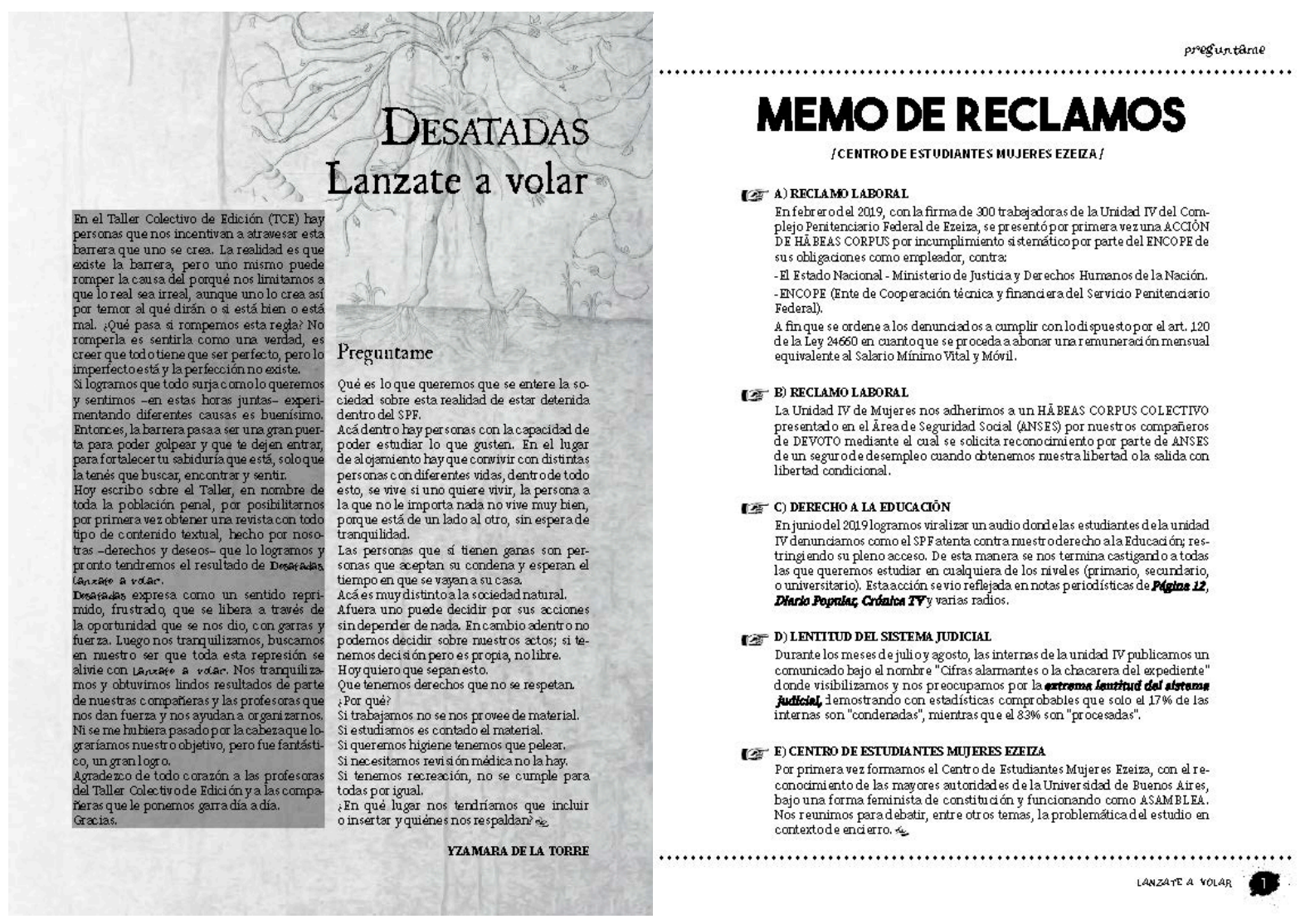

Desatadas 1 y 2. Página 1.

\section{La polisemia de nuestros nombres: sentidos y ambigüedades}

Una de las partes de la revista que más fuertemente condensa los sentidos que se ponen en juego cada semestre es su nombre. Pese a que se mantiene en el tiempo, se resignifica con cada edición, y esto puede verse plasmado en las revistas tanto como recuperarse de las conversaciones mantenidas durante el trascurso del taller. En ocasiones ha sido un punto de partida para la escritura, por lo que también existen textos publicados que reflexionan en torno a los nombres de las revistas.

La Resistencia recupera la pregunta por su propio nombre en más de una edición. En numerosos textos, algunos colectivos, otros firmados por miembros históricos del taller, se retoma la 
pregunta “Qué es La Resistencia?". Las respuestas que suscita han cumplido en su mayoría con la función del editorial, el texto que inicia la revista y que propone un tema clave que permite luego trazar ejes de lectura para el resto de la publicación.

En las primeras páginas del número 9 puede leerse un texto colectivo titulado "¿Quiénes somos? La Resistencia somos todos". Allí se define a La Resistencia, siempre con mayúsculas y en bastardilla, como un "antídoto" para el veneno que aleja de la sociedad, como un "accionar colectivo" y "solidario", como una alternativa a la "censura" y al "límite de expresión". Se hace hincapié en lo que la resistencia no es: no es "negarse a tal o cual cosa", incluso "no es solo resistir, es algo más....". Con estas últimas palabras cierra el texto, que por su carácter colectivo reúne voces diversas, estilos disímiles, distintas formas de aproximarse a la pregunta; juega con la ambigüedad entre la resistencia como concepto y La Resistencia como nombre de la revista, definiendo ambos a la vez.

En Los Monstruos Tienen Miedo, la pregunta en torno al nombre ha tomado diversas formas, muchas veces formuladas de manera espontánea durante las horas de taller. "¿Por qué se llama Los Monstruos?" y “iquiénes son los monstruos?" son las variantes más habituales. Las respuestas también han sido numerosas a lo largo de los años y sostienen abierta la discusión que se genera en el aula: ¿los monstruos son los otros o somos nosotros? "Actualmente vivo en una fortaleza custodiada por monstruos disfrazados de personas", señalan las primeras líneas del número 7, publicado en 2016, en un texto titulado "¿Por qué los monstruos?". Pero enseguida, continúa: "Se nos obliga a permanecer en esta vivienda, supuestamente porque somos personas cuyo grado de marginalidad constituye para la sociedad legal una monstruosidad que es imprescindible revertir". La monstruosidad, que en el principio del texto caracteriza a quienes "custodian la fortaleza", es asumida también como propia, pero no de manera individual sino como signo de una marginalidad supuesta y vivida colectivamente. "El problema radica en que los monstruitos que genera la sociedad anden sueltos por ahí, recordándole constante e impúdicamente a la sociedad sobre todo lo que falta arreglar en materia social", sentencia el texto, reconociendo que los monstruos que la sociedad crea se vuelven contra ella, para señalarle sus propias deficiencias.

Desatadas. Lanzate a volar, creada en 2019, contó ya en su primer número con un texto que remite a su propio nombre.

Desatadas expresa como un sentido reprimido, frustrado, que se libera a través de la oportunidad que se nos dio, con garras y fuerza. Luego nos tranquilizamos, buscamos en nuestro ser que toda esta represión se alivie con Lanzate a volar. Nos tranquilizamos y obtuvimos lindos resultados de parte de nuestras compañeras y las profesoras que nos dan fuerza y nos ayudan a organizarnos.

Publicado, como los anteriores, en la primera página de la revista, este fragmento da cuenta de un momento particular del taller: la instancia de elección del nombre que llevaría la revista. 
Luego de haber anotado durante varias semanas diferentes opciones, el colectivo realizó una votación para seleccionar el modo en que nombraríamos la nueva publicación. Si bien “Desatadas" tuvo el visto bueno general como opción preferida, hubo argumentos en contra. Para una de las compañeras del taller parecía remitir a personas fuera de control, llevadas por la ira. Otras argumentaron a favor, señalando que desatarse también significa liberarse de ataduras. Con el objetivo de mantener abierta la incógnita, para que Desatadas no remitiese solamente a un estado de desapaciguamiento, se decidió incorporar como subtítulo el segundo nombre más votado: Lanzate a volar. Así, sin cancelar el carácter polisémico del título principal, podíamos guiar la lectura en el sentido que, considerábamos, de otro modo no prevalecería: el de la libertad.

\section{Sentidos colectivos: la edición como debate y consenso}

Las escenas descritas en los apartados anteriores documentan, aunque parcialmente, la relación entre la propuesta metodológica del Taller Colectivo de Edición y las revistas editadas en ese marco. La dimensión editorial, como instancia de formulación de la escena enunciativa en la que se inscribe la revista merece, desde esta perspectiva, desplegarse y hacerse disponible a todas las personas cuyas voces promoverá la publicación. Establecer un modo de trabajo horizontal y colectivo en el marco de esta instancia permite que esas personas se impliquen y aporten su mirada, sus impresiones y valores en la producción de la revista. El trabajo sostenido en los centros universitarios donde desarrollamos el taller también nos implica como docentes en la construcción del territorio compartido con las y los estudiantes, una tarea que involucra fuertemente la discusión en torno a los sentidos de la práctica editorial en ese contexto.

Así, el colectivo editor permanece en el tiempo aunque sus integrantes varíen, y podemos reconocer el periódico resurgimiento de las preguntas y consideraciones relativas a las lecturas posibles de distintos grupos de destinatarios ideales. A lo largo de los años, la enunciación "tumbera", que en general se busca evitar, ha funcionado como una clave de lectura que valora positivamente el producto editorial tradicional y la fuerza legitimadora que le otorga la cultura hegemónica. El posicionamiento y la respuesta a los valores imperantes toman caminos más sutiles, de trabajo con la ambigüedad, definiciones esquivas, no solo por lo dicho en los textos sino también por la forma que asumen, desafiando géneros e incluso figuras autorales, al reunir distintas voces en un mismo escrito.

Los sentidos construidos a través de las revistas no se agotan en la práctica áulica de escritura y debate, sino que remiten a universos mucho más amplios donde se ponen en juego escenas enunciativas diversas, algunas de ellas tácitas. La revista se piensa como interpelación a otro que es a la vez la familia, el sistema penitenciario, los vecinos del barrio de origen y los que viven en las inmediaciones del penal, la sociedad detractora y la que apoya las causas que se plantean y defienden a lo largo de sus páginas. 


\section{Observaciones finales}

La edición, concebida como práctica que afecta voces ajenas y modifica su estatuto, es una tarea política y cultural que adquiere una dimensión particular al ejercerla en contextos de encierro. Allí las trabajamos con las voces de "personas con historias marcadas por la exclusión, por la marginación, por la privación de derechos" que, como indica Cynthia Bustelo en su tesis doctoral, aparecen "en la escena pública generalmente a través de otras voces que las narran".

Sus propias voces se encuentran silenciadas y no suelen salir a la escena social sino por discursos mediáticos, cargados de esa mirada externa y esquemática, teñida de un estigma social que los clasifica, los ordena, los exhibe como transgresores de la ley, y los condena (Bustelo, 2016: 229).

Proponer en este contexto un proyecto editorial, supone comprender la edición no solo como la producción de contenidos y soportes, sino que es por sí mismo un ejercicio de ampliación de derechos. Implica...

... centrar como nunca la atención en la voz que se edita, marginal, deslegitimada, ocultada, silenciada. Y abrir un espacio, "hacerle lugar al otro, en el sentido más verdadero del término". Es un editar por fuera de las lógicas del mercado, tal vez en su contra, retomando el carácter político de la edición: lo que la palabra y su tratamiento pueden lograr (o no) en términos de disputa del poder, en un ámbito de desempoderamiento casi total de los sujetos (Salgado, 2015).

Contraria a los métodos de trabajo de la edición entendida como industria cultural, en que la figura del editor concentra las decisiones relacionadas con la escena enunciativa en la que inscribe sus productos como parte de su distribución comercial, la propuesta pedagógica de editar colectivamente permite habilitar nuevos espacios de ejercicio de la palabra. En este marco se pueden crear y redefinir maneras de nombrarse y presentarse, construyendo lugares de enunciación en discursos propios.

En la cárcel, estas prácticas encuentran uno de sus límites en la institución misma que las aloja. En estos espacios es habitual constatar que "Los propósitos educativos y culturales se ven asediados por una lógica institucional dominante de premios y castigos, vigilancia y enmudecimiento" (Frugoni, 2018: 117). Esta lógica institucional no es encarnada solamente por funcionarios y trabajadores penitenciarios, sino que se hace presente también como eco en las aulas, durante los debates, de maneras imprevistas y recurrentes.

[...] nuestras propuestas entran en tensión con un umbral de transformación cuando en las condiciones del presente el testimonio como acto performativo señala no sólo las luchas por el derecho a la identi- 
dad sino la obligación de declarar quién se es como acto de autoexamen y constricción a los mecanismos de control, vigilancia y disciplinamiento (Delfino, Parchuc, 2017: 123).

Habilitar un espacio horizontal y colectivo de trabajo, en este contexto es una tarea siempre marcada por condiciones desfavorables. Editar, como tarea de promoción de voces deslegitimadas y silenciadas por el encierro, implica necesariamente atender al imperativo ético de evitar constituirse en una actividad en la que prevalezcan valores tácitos, bienintencionados pero ajenos, o contrarios al deseo y la conveniencia de las personas implicadas.

Esto implica considerar que proyectos o formatos editoriales cargados de valores positivos, dentro de ciertas comunidades lectoras podrían cambiar de signo en otros ámbitos. Tomar como referencia tendencias estéticas y conceptuales opuestas a la lógica comercial de las industrias culturales o de la cultura hegemónica, es un movimiento posible siempre que no se repliquen acríticamente sus estrategias. Solo a condición de que las decisiones editoriales sean compartidas puede una publicación constituirse como una tarea política orientada a la promoción de las voces relegadas en el marco de una perspectiva de ampliación de derechos.

\section{Referencias}

Bustelo, C. (2017). Experiencias educativas en contextos de encierro. Un abordaje político pedagógico desde la perspectiva narrativa y (auto) biográfica. Tesis de doctorado, Facultad de Filosofía y Letras, Universidad de Buenos Aires.

Chartier, R. (1993). De la historia del libro a la historia de la lectura. Libros, lecturas y lectores en la Edad Moderna. Madrid: Alianza Universidad.

Chauvin, S. (2016). Taller Colectivo de Edición en el Centro Universitario de Devoto: inclusión educativa en primera persona. Ensayo final para la Especialización Docente de Nivel Superior en Educación en Contextos de Encierro.

De Certeau, M. (1980). Leer, una cacería furtiva. La invención de lo cotidiano 1. Artes de hacer. México: Universidad Iberoamericana.

Delfino, S.; J. Parchuc (2017). Narrar para reescribir: experiencias pedagógicas en contextos de encierro. En A. Gerbaudo; I. Tosti (eds.). Nano-intervenciones con la literatura y otras formas del arte. Santa Fe: Universidad Nacional del Litorial, 109-142.

Fabiani, J-L. (1997). Políticas y prácticas de la lectura en prisión: el caso francés. Educación y biblioteca, 9(85), 61-65.

Frugoni, S. (2018). Bibliotecas Itinerantes, lecturas y mediadores en contextos de encierro. Catalejos. Revista sobre lectura, formación de lectores y literatura para niños, (7), 114-126.

Gaudio, A. et al. (2013). Lógicas editoriales en el encierro: el Taller Colectivo de Edición. Seminario Taller sobre Educación Universitaria en Cárceles. De las buenas intenciones a las buenas prácticas. Buenos Aires: Facultad de Derecho-Universidad de Buenos Aires. 
Kunin, J. (2013). La multiplicación de las editoriales cartoneras latinoamericanas: análisis de un caso de apropiación/es de sentidos. Ponencia en I Jornadas Interdisciplinarias de Jóvenes Investigadores en Ciencias Sociales. Argentina: UNSAM.

Petz, I. (2015). Extensión universitaria. Redes de extensión, (1). Buenos Aires: Facultad de Filosofía y Letras-Universidad de Buenos Aires.

Rubín, M. J. (2019). La actividad editorial intramuros como práctica cultural de extensión universitaria. +E: Revista de Extensión Universitaria, 9(11), 196-214. https://doi.org/10.14409/extension.v9i11.Jul-Dic.8723

Rubín, M. (2020). Políticas y dinámicas editoriales en contextos de encierro: la experiencia del Taller Colectivo de Edición. En Parchuc; et al. Escribir en la cárcel. Prácticas y experiencias de lectura y escritura en contextos de encierro. Buenos Aires: Editorial de la Facultad de Filosofía y Letras.

Schmied, A. (2018). Prólogo del editor. En Giuliani, A. Editores y política. Entre el mercado latinoamericano de libros y el primer peronismo (1938-1955). Temperley: Tren en Movimiento.

Segato, R. (2003). El sistema penal como pedagogía de la irresponsabilidad y el proyecto "habla preso: el derecho humano a la palabra en la cárcel". Brasilia: Universidad de Brasilia. http:// lanic.utexas.edu/project/etext/lilas/cpa/spring03/culturaypaz/segato.pdf

Vanoli, H. (2009). Pequeñas editoriales y transformaciones en la cultura literaria argentina. Apuntes de Investigación del CECYP, (15), 161-185.

Venturini, S. (2015). Micropolíticas de la edición y de la traducción: el caso de Colección Chapita. Cuadernos LIRICO, (13).

\section{Materiales de consulta}

La Resistencia, Los Monstruos Tienen Miedo, Desatadas. Lanzate a Volar. Revistas de Extensión. Buenos Aires: Facultad de Filosofía y Letras-Universidad de Buenos Aires. http://seube.filo.uba.ar/banner/revistas-de-extensión 